DOI:

Cite this as:

Prajalani, Yuniviana Nur Hari, Himawanto, Dwi Aries. Aksesibilitas Bagi Anak Berkebutuhan Khusus di SLB

Negeri Sukoharjo. Indonesian Journal of Disability Studies (IJDS). 2017: Vol. 04(02): PP 87 - 95.

\title{
Aksesibilitas Bagi Anak Berkebutuhan Khusus di SLB Negeri Sukoharjo
}

\author{
${ }^{1 *}$ Yuniviana Nur Hari Prajalani, ${ }^{2}$ Dwi Aries Himawanto \\ 1Magister Pendidikan Luar Bisa, Universitas Sebelas Maret, Surakarta,Indonesia \\ 2Jurusan Teknik Mesin, Universitas Sebelas Maret, Surakarta, Indonesia \\ Jl. Ir. Sutami No. 36A, Surakarta, Jawa Tengah 56126
}

\begin{abstract}
Abstrak: This study aims to determine and evaluate the availability of facilities and accessibility of buildings in the SLB Negeri Sukoharjo for children with special needs, especially blind and physical impairment. The research method used is a qualitative research. Data were collected by observation, documentation, and interview techniques. Data analysis using qualitative description by comparing data obtained from the field with the standard provisions according to the Minister of Public Works Decree Number 30 of 2006 which regulates the technical guidance of facilities and accessibility of buildings and the environment. The results showed that accessibility for the blind and physical impairment in SLB Negeri Sukoharjo less accessible. Therefore, there needs to be improvement efforts in some parts of the building of SLB Sukoharjo to make it more accessible for PwDs.
\end{abstract}

Keywords: accessibility, children with special needs, SLB

\section{Latar Belakang}

Sekolah Luar Biasa (SLB) merupakan suatu lembaga pendidikan yang dikhususkan bagi anak-anak yang memiliki kebutuhan khusus. Anak berkebutuhan khusus adalah anak yang dalam pendidikan memerlukan pelayanan yang spesifik, berbeda dengan anak pada umumnya (Salim\&Yusuf, 2009). Anak berkebutuhan khusus diantaranya adalah tunanetra, tunarungu, tunagrahita, tunadaksa, dan tunalaras. Fokus dalam penelitian ini adalah anak yang mengalami hambatan fisik, yaitu tunanetra dan tunadaksa. Anak berkebutuhan kusus juga memiliki hak yang sama seperti halnya anak normal lainnya terutama dalam hal pendidikan. Salah satu lembaga pendidikan yang diperuntukkan bagi Anak Berkebutuhan Khusus adalah SLB. Dalam penerapan pembelajaran di sekolah, hendaknya tidak hanya berfokus pada kurikulum dan pembelajaran yang khusus digunakan bagi anak disabilitas, melainkan

* Corresponding author: Yuniviana Nur Hari Prajalani yuniviananur@student.uns.ac.id

Published online at http://IJDS.ub.ac.id/

Copyright $@$ C 2017PSLD UB Publishing. All Rights Reserved juga harus memperhatikan fasilitas yang digunakan sebagai penunjang ketika di sekolah. Bangunan Sekolah Luar Biasa hendaknya memiliki fasilitas yang memadai bagi penyandang disabilitas, karena Sekolah Luar Biasa merupakan wadah utama untuk menampung anak-anak berkebutuhan khusus, sehingga untuk mewujudkan aksesibilitas yang layak harus dimulai dari hal yang utama terlebih dahulu agar untuk lembaga lainnya seperti sekolah inklusi dapat menerapkan hal tersebut.

Aksesibilitas merupakan tingkat kemudahan yang dicapai oleh seseorang terhadap suatu objek di lingkungannya. Dalam UU No. 8 Tahun 2016 Pasal 1 (8) menjelaskan bahwa Aksebilitas adalah kemudahan yang disediakan untuk penyandang disabilitas guna mewujudkan kesamaan kesempatan. Penerapan aksesibilitas dalam Sekolah Luar Biasa ditujukan untuk memberikan suasana yang aman dan nyaman bagi anak ketika sedang proses pembelajaran maupun ketika sedang berada di lingkungan sekolah. Di lingkungan SLB terkadang masih banyak yang belum memperhatikan mengenai aksesibilitas bagi siswa siswinya. Dalam mendesain bangunan untuk pendidikan terutama SLB harus memperhatikan standar bangunan 
berdasarkan ketntuan standar menurut Permen Nomor 30 Tahun 2006 mengenai Pedoman Teknis Fasilitas dan Aksesibilitas pada Bangunan Gedung dan Lingkungan. Pedoman teknis ini dimaksudkan untuk memberikan acuan bagi kegiatan pembangunan, yang meliputi perencanaan teknis dan pelaksanaan konstruksi serta pemanfaatan bangunan gedung dan lingkungan yang aksesibel bagi semua anak dengan mengutamakan penyandang cacat terutama anak tunadaksa dan tunanetra. Dalam pembangunan harus memperhatikan asas fasilitas dan aksesibilitas yang meliputi, keselamatan, kemudahan, kegunaan, dan kemandirian.

Penelitian sebelumnya mengenai aksesibilitas telah banyak dilakukan, namun belum banyak penelitian mengenai bangunan Sekolah Luar Biasa yang mana sekolah tersebut merupakan lingkungan pendidikan utama bagi anak berkebutuhan khusus. Kebanyakan orang berpandangan bahwa Sekolah Luar Biasa sudah menyediakan fasilitas dan aksesibilitas yang sesuai untuk Anak Berkebutuhan Khusus. Namun kenyataannya tidak demikian, hasil penelitian sebelumnya menunjukkan bahwa fasilitas dan aksesibilitas sebagian besar belum memadai. Penelitian yang dilakukan oleh Ulfa dkk (2016) pada bangunan gedung pendidikan menunjukan bahwa aksesibilitas pada gedung tersebut masih kurang aksesibel bagi penyandang tunanetra. Hal tersebut ditunjukkan dengan belum adanya ramp, tanda braille, guiding block, dan tempat parkir yang tertata tidak rapi. Padahal kehadiran aksesibilitas pada fasilitas umum maupun bangunan sangat dibutuhkan bagi penyandang disabilitas. Penelitian yang dilakukan Widi dan Nirwansyah (2013) menyimpulkan bahwa bangunan sekolah utamanya Sekolah Khusus atau Sekolah Luar Biasa sangat perlu mengutamakan aksesibilitas sirkulasi maupun desain dari interior hingga eksteriornya, sehingga pencapaian rasa aman dan nyaman dalam melakukan aktivitas belajar mengajar dapat terlaksana. Panjankar (2016) menyatakan bahwa aksesibilitas sangat penting untuk sekolah. Jika aksesibilitas sekolah tidak tepat, hasilnya mungkin siswa akan putus sekolah.

Berdasarkan uraian tersebut, penelitian ini bertujuan untuk mengetahui dan mengevaluasi aksesibiliatas bangunan SLB Negeri
Sukoharjo bagi anak-anak berkebutuhan khusus. Sehingga sekolah yang menampung anak berkebutuhan khusus dapat menyediakan fasilitas dan aksesibilitas dengan baik.

\section{Tinjauan Pustaka}

Aksesibilitas adalah kemudahan yang diberikan kepada para penyandang cacat, berupa pengadaan atau modifikasi sarana dan prasarana kehidupan sehari-hari, termasuk lingkungan fisik, yang disesuaikan dengan kondisi dan kebutuhan penyandang cacat, agar mereka dapat melakukan aktivitas sehari-hari secara mandiri (Tarsidi, 2008).

Menurut World Health Organization, penyandang cacat adalah orang yang mungkin miskin dalam hal fisik, kognitif, mental, sensoris, emosional dan perkembangan atau beberapa kombinasi ini (Hashim, 2012)

Menurut Hurst dikatakan bahwa aksesibilitas adalah ukuran dari kemudahan (waktu, biaya, atau usaha) dalam melakukan perpindahan antara tempat-tempat atau kawasan dalam sebuah sistem (dalam Magribi \& Suhardjo, 2004). Menurut Lubis, aksesibilitas wajib diterapkan secara optimal, guna mewujudkan kesamaan kesempatan dalam mencapai segala aspek kehidupan dan penghidupan, menuntut adanya kemudahan dan keselamatan bagi semua pengguna tanpa terkecuali (Arrachmin, 2012). Kesamaan kesempatan bagi difabel dalam segala aspek kehidupan dan penghidupan dilaksanakan melalui penyediaan aksesibilitas (Mujimin, 2007)

Berdasarkan pendapat tersebut dapat disimpulkan bahwa aksesibilitas merupakan kemudahan yang disediakan bagi penyandang cacat yang diterapkan secara masksimal agar tercapai kesamaan kesempatan dalam berbagai kehidupan. Jadi, Pemerataan pelayanan dalam aspek kehidupan meliputi pelayanan fasilitas dan aksesibilitas bagi anak berkebutuhan khusus.

Anak berkebutuhan khusus merupakan anak yang memiliki kemampuan yang berbeda dengan anak pada umumnya. Anak berkebutuhan khusus atau sering disebut penyandang cacat atau disabilitas merupakan individu yang membutuhkan pendidikan khusus dan layanan khusus. Menurut Undang- 
undang Republik Indonesia No 8 Tahun 2016 tentang penyandang disabilitas, penyandang disabilitas adalah setiap orang yanga lainnya berdasarkan kesamaan hak. Menurut Shollahudin (2007), dissability adalah perubahan kondisi fisik atau mental seseorang sehingga mengakibatkan terbatasanya kemampuan yang normal dalam berfungsi dan beraktifitas. Menurut Goldsmith difabel didefinisikan sebagai orang yang memiliki gangguan fisik dan tidak mampu untuk menggunakan fasilitas bangunan karena tidak tersedianya fasilitas pendukung bagi kemudahan mereka (Idris, 2015). Penyandang cacat/disability berhak untuk mendapatkan kesempatan yang sama seperti anak pada umumnya. Siswa penyandang cacat harus mendapatkan akses yang setara terhadap peluang yang akan menjamin hasil yang berhasil di bidang pendidikan, ketenagakerjaan dan integrasi masyarakat (Ajuwon, 2008).

Aksesibilitas sebuah infrastruktur pada sebuah bangunan merupakan hal yang paling penting untuk menunjang keamanan dan kenyamanan semua orang yang ada di dalamnya. Tidak terkecuali bagi penyandang disabilitas, khususnya tunadaksa. Mereka yang memiliki kekurangan di dalam mobilisasi dan memerlukan alat bantu seperti tongkat, braces, frames, bahkan kursi roda sangat kurang nyaman bilamana sebua sarana dan prasarana di dalam bangunan tidak memenuhi kriteria persyaratan aksesibilitasnya (Jefri, 2016). Halhal yang berkaitan dengan aksesibilitas adalah bangunan, elemen bangunan, kamar kecil (toilet), pintu, ramp, ruang, ruang lantai bebas, rute aksesibel, tangga (Holmes dalam Sholahuddin, 2007). Dalam penerapan aksesibilitas harus menerapkan berbagai asas agar tercapai tujuan yang dikehendaki. Berdasarkan Permen PU Nomor 30 tahun 2006 asas fasilitas dan aksesibilitas meliputi:

a) Keselamatan, yaitu setiap bangunan yang bersifat umum dalam suatu lingkungan terbangun, harus memperhatikan keselamatan bagi semua orang;

b) Kemudahan, yaitu setiap orang dapat mencapai semua tempat atau bangunan yang bersifat umum dalam suatu lingkungan;

c) Kegunaan, yaitu setiap orang harus dapat mempergunakan semua tempat atau bangunan yang bersifat umum dalam suatu lingkungan;

d) Kemandirian, yaitu setiap orang harus bisa mencapai, masuk dan mempergunakan semua tempat atau bangunan yang bersifat umum dalam suatu lingkungan dengan tanpa membutuhkan bantuan orang lain.

Pentingnya aksesibilitas bagi penyandang disabilitas adalah untuk menjamin kemandirian dan partisipasi mereka dalam segala bidang kehidupan di masyarakat (Syafiie, 2014). Akses fisik memiliki pengaruh besar apakah siswa dapat sepenuhnya berpartisipasi dalam lingkungan sekolah (Egilson\&Traustadottir, 2009)

Selain memperhatikan peraturan menteri tersebut, dalam penerapan bangunan juga harus memperhatikan Universal Design. Universal design dapat didefinisikan sebagai desain produk dan lingkungan yang dapat digunakan oleh semua orang, semaksimal mungkin, tanpa disain khusus untuk sekelompok orang tertentu (College of Design dalam Kadir, 2012).

\section{Metodologi Penelitian}

Metode penelitian yang digunakan dalam penelitian ini adalah penelitian kulitatif. Desain yang digunakan yaitu penelitian deskriptif kualitatif, karena peneliti bermaksud untuk menggambarkan secara deskriptif kondisi nyata mengenai penyediaan fasilitas dan aksesibilitas bagi anak berkebutuhan khusus (tunanetra dan tunadaksa) di SLB Negeri Sukoharjo.

Subjek dari penelitian ini yaitu penyandang disabilitas tunanetra dan tunadaksa. Narasumber penyandang tunanetra adalah salah seorang guru yang bekerja di sekolah tersebut, sedangkan narasumber penyandang disabilitas tunadaksa merupakan salah satu murid SMALB di sekolah tersebut. Sedangkan objek dari penelitian ini meliputi : area parkir, jalur pemandu, jalur pedestrian, ramp, ruang kelas, pintu, toilet/kamar mandi, dan wastafel.

Teknik pengumpulan data dilakukan dengan observasi, dokumentasi, dan wawancara. Observasi dilakukan dengan menggunakan instrumen checklist yang disusun berdasarkan Permen PU Nomer 30 
Tahun 2006, sedangkan wawancara dilakukan terhadap guru tunanetra dan siswa SMALB tunadaksa. Analisis data menggunakan deskripsi kualitatif dengan membandingkan data yang diperoleh dari lapangan dengan ketentuan standar menurut Permen PU Nomor 30 Tahun 2006 yang mengatur mengenai Pedoman Teknis Fasilitas dan Aksesibilitas pada Bangunan Gedung dan Lingkungan.

\section{Hasil dan Pembahasan}

Berdasarkan hasil pengamatan yang dilakukan melalui observasi, wawancara dan dokumentasi foto, dapat dideskripsikan hal-hal sebagai berikut:

\subsection{Kondisi Geografis Bangunan SLB Negeri Sukoharjo}

SLB Negeri Sukoharjo beralamatkan di Dalangan RT 02 RW 02 Klaseman, Gatak Sukoharjo Kode Pos 57557 dengan luas tanah $7155 \mathrm{~m}^{2}$. SLB Negeri Sukoharjo memiliki sarana dan prasarana yang diperuntukkan bagi anak berkebutuhan khusus. Di SLB Negeri Sukoharjo terdapat 63 ruangan yang terdiri dari ruang guru, ruang kepala sekolah, ruang kelas sebanyak 26 ruangan, ruang olahraga, ruang keterampilan, ruang UKS, ruang tata usaha, ruang sirkulasi, ruang perpustakaan, ruang bina diri dan bina gerak, laboratorium komputer, mushola, aula, unit produksi, kamar mandi sebanyak 12 ruang, koperasi, ruang penjaga sekolah, dapur dan asrama siswa sebanyak 8 ruangan. SLB ini memiliki lapangan sepak bola dan GOR sebagai sarana untuk melakukan aktivitas fisik.

\subsection{Analisis aksesibilitas Bangunan SLB \\ Negeri Sukoharjo berdasarkan Permen PU \\ Nomor 30 tahun 2006}

Permen PU Nomor 30 tahun 2006 mengatur tentang persyaratan teknis fasilitas dan aksesibilitas pada bangunan gedung dan lingkungan yang meliputi: a) ukuran dasar ruang; b) jalur pedestrian; c) jalur pemandu; d) area parkir; e) pintu; f) ram; g) tangga; h) lift; i) lift tangga (stairway lift); j) toilet; $\mathrm{k}$ ) pancuran; 1) wastafel; m) telepon; n) perlengkapan dan peralatan kontrol; o) perabot; dan p) rambu dan marka.
Observasi pada bangunan SLB Negeri Sukoharjo meliputi beberapa objek diantaranya : area parkir, jalur pemandu, jalur pedestrian, ramp, ukuran dasar ruang (ruang kelas), pintu, toilet/kamar mandi, dan wastafel.

\subsubsection{Area parkir}

Berdasarkan Permen PU Nomor 30 tahun 2006 area parkir adalah tempat parkir kendaraan yang dikendarai oleh penyandang cacat, sehingga diperlukan tempat yang lebih luas untuk naik turun kursi roda, daripada tempat parkir yang biasa. Sedangkan daerah untuk menaik-turunkan penumpang (Passenger Loading Zones) adalah tempat bagi semua penumpang, termasuk penyandang cacat, untuk naik atau turun dari kendaraan. Tempat parkir yang aksesibel harus memenuhi beberapa persyaratan.

Di SLB Negeri Sukoharjo terdapat dua tempat parkir, yang mana tempat parkir satu digunakan untuk parkir guru dan karyawan sedangkan tempat parkir yang kedua digunakan untuk siswa dan orang tua wali. Dalam observasi ini mengevaluasi tempat parkir yang kedua yang mana digunakan sebagai tempat parkir bagi salah satu siswa tunadaksa di sekolah tersebut.

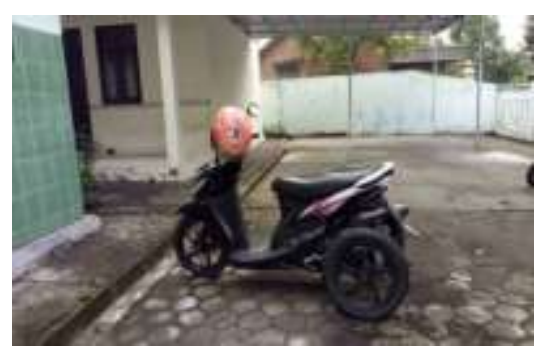

Gambar 1. Tempat Parkir Siswa Tunadaksa dan Orang Tua Wali

Berdasarkan observasi yang dilakukan, belum ada area parkir khusus bagi penyandang disabilitas. Kendaraan yang telah dimodifikasi bagi anak tunadaksa tidak dapat masuk dalam area parkir. Sehingga tidak ada ruang bebas bagi kendaraan pengguna kursi roda untuk masuk dan keluar. Kendaraan anak tunadaksa diparkirkan di halaman terbuka di sebelah lahan parkir. Hal itu dilakukan karena apabila parkir tersebut penuh anak kesulitan jika ingin keluar dari parkiran. Dari 5 aspek pada instrumen, hanya 1 aspek yang terpenuhi. Area 
parkir ini belum memenuhi persyaratan teknis fasilitas dan aksesibilitas berdasar Permen PU Nomor 30 Tahun 2006. Sehingga dapat dikatakan bahwa area parkir ini belum aksesibel bagi penyandang disabilitas.

\subsubsection{Jalur Pemandu}

Berdasarkan Permen PU Nomor 30 tahun 2006, jalur pemandu merupakan jalur yang memandu penyandang cacat untuk berjalan dengan memanfaatkan tekstur ubin pengarah dan ubin peringatan.

Pada bangunan SLB Negeri Sukoharjo terdapat 6 banjar bangunan. Di salah satu banjar yaitu di sisi bangunan paling kanan terdapat ubin yang berbeda yang mana ditujukan sebagai jalur pemandu bagi penyandang disabilitas. Namun, jika di sesuaikan dengan Permen PU Nomor 30 Tahun 2006, jalur pemandu yang ditujukan bagi penyandang disabilitas ini kurang sesuai. Tekstur ubin pengarah dan ubin peringatan hanya menyerupai model standar, tekstur yang digunakan kurang timbul. Berdasarkan ketentuan standar, untuk membedakan antara ubin pemandu dengan ubin lainnya maka pada ubin pemandu diberi warna kuning atau jingga. Berdasarkan fakta di lapangan, jalur pemandu di SLB Negeri Sukoharjo belum aksesibel, berdasarkan hasil wawancara dengan salah satu guru tunanetra menjelaskan bahwa masih terlalu sulit untuk membaca jalur pemandu tersebut.

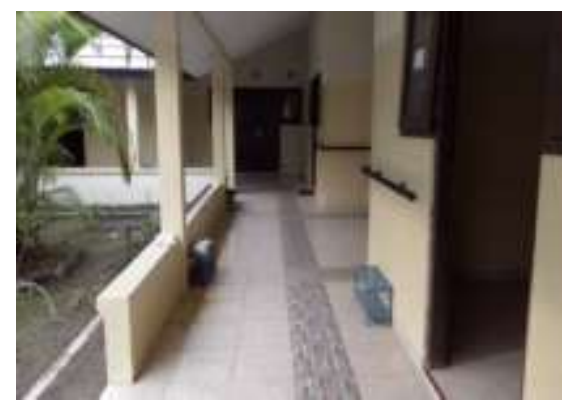

Gambar 2. Jalur pemandu pada bangunan sebelah kanan.

\subsubsection{Jalur Pedestrian}

Jalur pedestrian merupakan jalur yang digunakan untuk berjalan kaki atau berkursi roda bagi penyandang cacat secara mandiri yang dirancang berdasarkan kebutuhan orang untuk bergerak aman, mudah, nyaman dan tanpa hambatan (Permen Nomer 30 Tahun 2006).

Di SLB Negeri Sukoharjo belum terdapat jalur pedestrian yang layak, berdasarkan hasil observasi jalan untuk menuju ke ruang kelas masih minim, dalam artian jalan masih banyak berlubang dan terdapat gundukan di jalan. Terlebih untuk penyandang disabilitas tunadaksa, hal ini sangat menyulitkan akses menuju ke kelas. Penyandang tunadaksa di sekolah tersebut biasanya melewati jalan di depan kelas lainnya karena jalan tersebut dirasa halus dan mudah untuk dilewati kursi roda. Namun kesulitannya ketika terdapat perbedaan tinggi lantai dengan permukaan jalan yang tidak didukung dengan ram. Penyandang tunadaksa harus membutuhkan bantuan orang lain untuk melakukan hal tersebut. Berdasarkan data yang telah didapatkan, jalur pedestrian di sekolah ini kurang memenuhi standar. Jika dibandingkan dengan Permen PU Nomor 30 Tahun 2006, dari 7 aspek persyaratan jalur pedestrian hanya 2 aspek yang terpenuhi, sehingga dapat dikatakan bahwa jalur pedestrian di sekolah ini belum aksesibel bagi penyandang disabilitas.

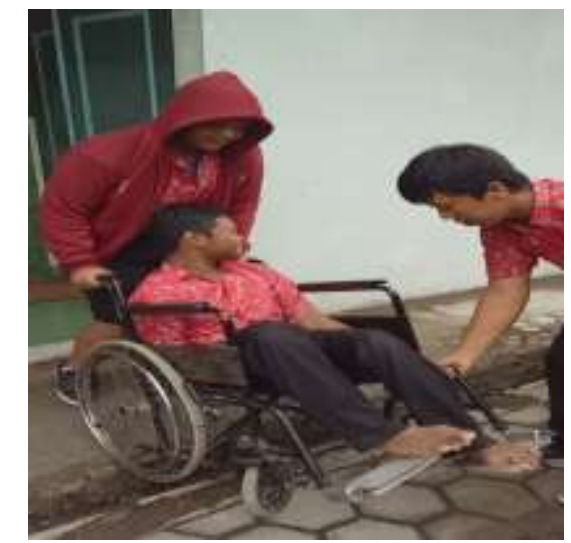

Gambar 3. Anak melewati jalan ke kelas dengan bantuan temannya

\subsubsection{Ram}

Ram adalah jalur sirkulasi yang memiliki bidang dengan kemiringan tertentu, sebagai alternatif bagi orang yang tidak dapat menggunakan tangga.

Pada bangunan di SLB Negeri Sukoharjo sudah terdapat ram dan ada juga sisi yang tidak diberi ram. Ram di bangunan SLB Negeri Sukoharjo berjumlah 9. Pada 
permukaan ram memiliki tekstur yang halus, sehingga terkadang licin ketika hujan. Untuk lebar dan panjang ram sebagian sudah sesuai dengan ukuran standar. Namun, fasilitas ram di sekolah ini belum dilengkapi dengan pegangan rambatan dan belum ada pengaman ram..

Berdasarkan data tersebut dapat dikatakan bahwa fasilitas ram belum aksesibel bagi penyandang disabilitas, meskipun satu dua persyaratan telah dipenuhi.

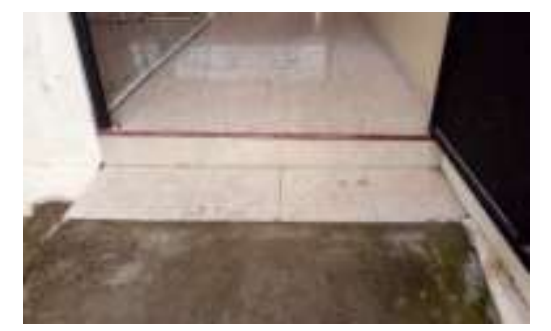

Gambar 4. Bangunan yang belum memiliki ram

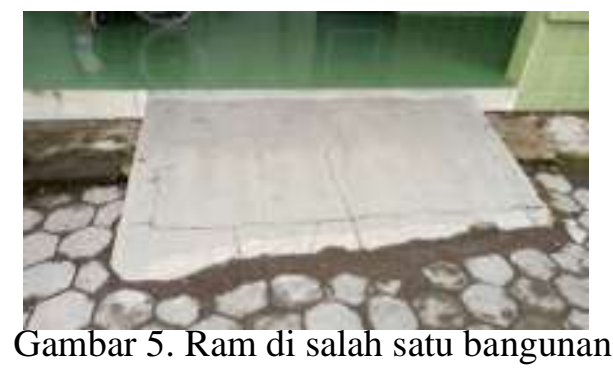

\subsubsection{Ukuran Dasar Ruang}

Ukuran dasar ruang tiga dimensi (panjang, lebar, tinggi) mengacu kepada ukuran tubuh manusia dewasa, peralatan yang digunakan, dan ruang yang dibutuhkan untuk mewadahi pergerakan penggunanya (Permen PU Nomor 30 tahun 2006). Ruang diartikan sebagai suatu petak yang dibatasi oleh dinding dan atap baik oleh unsur yang permanen ataupun tidak permanen. Dalam kaitannya dengan manusia, hal paling penting dari pengaruh ruang terhadap perilaku manusia adalah fungsi atau pemakaian dari ruang tersebut (Haryadi , 1995). Perancangan fisik dari setting ruang yang mempengaruhi perilaku pemakai adalah ukuran \& bentuk ruang, perabot \& penataanya, warna ruang, suara, temperatur \& pencahayaan.

Observasi ruang dalam penelitian ini yaitu mengambil satu sampel ruang kelas, yang mana ruang tersebut digunakan selama proses pembelajaran bagi anak penyandang disabilitas. Penataan bagi ruang kelas anak berkebutuhan khusus pada intinya sama saja dengan penataan pada ruang kelas orang normal, hanya saja perbedaaan terletak pada sirkulasinya (Widi dan Nirwansyah , 2013).

Berdasarkan observasi ukuran dasar ruang yang diterapkan sebagai fungsi ruang kelas sebagian sudah sesuai. Penempatan perabot diletakan di bagian pojok ruangan agar tidak mengganggu penyandang disabilitas. Ruang gerak bagi pemakai kruk, kursi roda maupun tongkat tunanetra sudah sesuai dan dapat memenuhi standar jangkauan ke samping dan depan. ,oleh karena itu ruang kelas dikatakan aksesibel bagi penyandang tunadaksa.

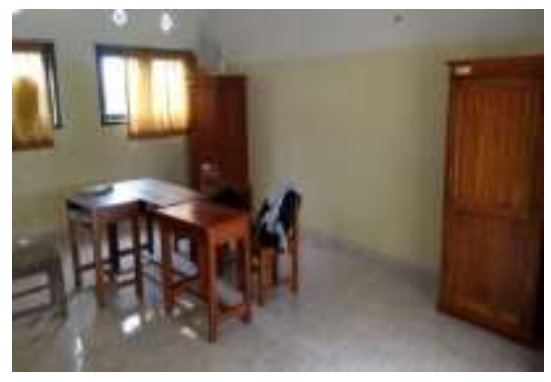

Gambar 6. Ruang Kelas

\subsubsection{Pintu}

Berdasarkan Permen PU Nomor 30 tahun 2006, pintu adalah bagian dari suatu tapak, bangunan atau ruang yang merupakan tempat untuk masuk dan keluar dan pada umumnya dilengkapi dengan penutup (daun pintu).

Pintu untuk keluar/masuk kelas terutama kelas bagi penyandang disabilitas tunadaksa merupakan pintu dengan satu daun pintu yang hanya terbuka ke satu arah. Di bagian pintu belum terdapat plat tendang yang biasanya diletakkan di bagian bawah pintu yang diperlukan bagi pengguna kursi roda dan tongkat tunanetra. Antara ruang kelas dengan bagian luar kelas masih terdapat beda ketinggian, hal ini menyulitkan anak tunadaksa untuk masuk ke ruang kelas secara mandiri.

Berdasarkan data tersebut, pintu masuk kelas kurang aksesibel bagi penyandang disabilitas. Karena belum memenuhi semua persyaratan dalam Permen PU Nomor 30 tahun 2006. 


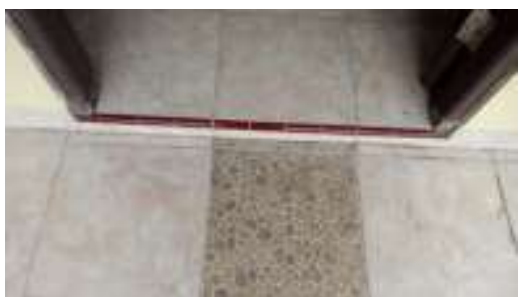

Gambar 7. Pintu Masuk kelas

\subsubsection{Toilet/ Kamar Mandi}

Toilet/kamar mandi merupakan salah satu fasilitas yang diharuskan dalam setiap bangunan, karena kehadiran kamar mandi sangat dibutuhkan bagi setiap orang. Berdasarkan Permen PU Nomor 30 Tahun 2006 esensi dari toilet merupakan fasilitas sanitasi yang aksesibel untuk semua orang, termasuk penyandang cacat dan lansia pada bangunan atau fasilitas umum lainnya. Toilet atau kamar kecil umum yang aksesibel harus dilengkapi dengan tampilan rambu/simbol dengan sistem cetak timbul pada bagian luarnya. Toilet pada bangunan ini tidak terdapat rambu atau simbol penyandang disabilitas. Pada bagian dalam kamar mandi sudah memiliki ruang yang cukup untuk masuk dan keluar pengguna kursi roda. Namun untuk ketinggian tempat duduk kloset belum sesuai dengan ketinggian pengguna kursi roda yaitu sekitar $45-50 \mathrm{~cm}$. Untuk jenis closet masih menggunakan bentuk jongkok semua. Bahan ubin yang digunakan di lantai kamar mandi tidak licin. Untuk bagian kunci pintu sudah mampu dijangkau bagi penyangdang disabilitas. Di dalam toilet belum dilengkapi dengan peganggan rambat, namun di bagian luar toilet sudah terdapat pegangan rambat/handrail. Di bagian daerah pintu kamar mandi belum disediakan tombol bunyi guna sewaktu-waktu terjadi sesuatu yang tidak diharapkan.

Berdasarkan deskripsi tersebut, kamar mandi pada bangunan sekolah ini belum aksesibel bagi penyangdang disabilitas, karena terdapat beberapa persayaratan standar yang belum terpenuhi. Dari 8 aspek persyaratan toilet/kamar mandi, hanya 3 aspek yang terpenuhi.

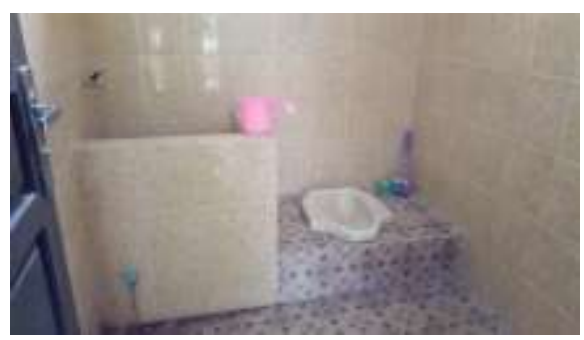

Gambar 8. Toilet/Kamar Mandi

\subsubsection{Wastafel}

Wastafel merupakan fasilitas cuci tangan, cuci muka, berkumur atau gosok gigi yang bisa digunakan untuk semua orang. Pemasangan wastafel harus memperhatikan standar berdasarkan Permen PU Nomor 30 Tahun 2006 agar dapat juga digunakan bagi penyandang disabilitas. Dalam pemasangannya, wastafel harus dipasang sedemikian sehingga gar dapat dijangkau penyandang disabilitas. Tinggi permukaannya dan lebar depannya dapat dimanfaatkan oleh pengguna kursi roda dengan baik. Terdapat ruang gerak yang cukup yang disediakan di depan wastafel dan di bawah wastafel sehingga tidak menghalangi lutut dan kaki pengguna kursi roda. Kran yang digunakan seharusnya didesain dengan sistem pengungkit.

Berdasarkan observasi pemasangan wastafel di sekolah ini kurang aksesibel, jarak antara kursi roda dengan watafel terlalu jauh, karena di bawah wastafel terdapat kotak penghalang seperti di gambar.

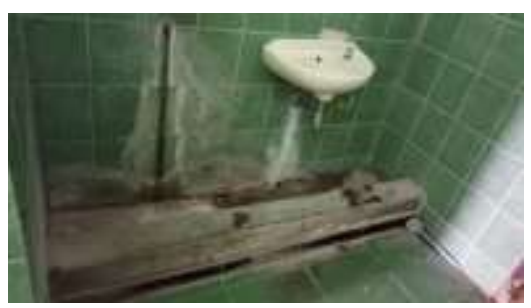

Gambar 9. Wastafel

\section{Penutup}

Berdasarkan hasil penelitian yang telah dilakukan dapat disimpulkan bahwa aksesibilitas di SLB Negeri Sukoharjo masih kurang aksesibel. Hal ini dikarenakan fasilitas yang teredia belum merujuk pada ketentuan standar Permen PU Nomor 30 tahun 2006. Sehingga fasilitas kurang memadai untuk mempermudah tunanetra dan tunadaksa 
berpindah dari satu tempat ke tempat yang lain secara mandiri tanpa adanya hambatan.

Untuk mewujudkan Sekolah Luar Biasa yang ramah terhadap penyandang disabilitas, maka diperlukan perbaikan secara bertahap pada area parkir, jalur pemandu, jalur pedestrian, ram, ruang kelas, pintu, toilet/kamar mandi, dan wastafel.

Keterlibatan berbagai pihak, seperti kementrian pendidikan dan kebudayaan, pemerintah daerah, serta warga sekolah dalam hal ini sangat diperlukan untuk mewujudkan Sekolah Luar Biasa yang ramah difabel yang dapat menyediakan berbagai fasilitas dan aksesibilitas bagi penyandang disabilitas.

\section{Daftar Pustaka}

Ajuwon, Paul M. (2008). Inclusive Education For Students With Disabilities In Nigeria: Benefits, Challenges And Policy Implications. International Journal Of Special Education, Vol 23, No 3, pp. 11-16.

Arrachim, Yazied H. (2012). Aksesibilitas Bagi Anak Berkebutuhan Khusus dalam Lingkup Pendidikan Inklusi di Sekolah Dasar Inklusi di Kabupaten Ssragen tahun 2012. Skripsi: Universita Sebelas Maret.

Egilson, S. T., \& Traustadottir, R. (2009). Participation of students with physical disabilities in the school environment. American Journal of Occupational Therapy, 63, pp 264-272.

Haryadi, B Setiawan. (1995). Arsitektur Lingkungan Dan Perilaku. Yogyakarta. Direktorat Jendral Pendidikan

Hashim, A.F, dkk. (2012). Access and Accessibility Audit in Commercial Complex: Effectiveness in Respect to People with Disabilities (PWDs). Procedia - Social and Behavioral Sciences 50, pp. 452 - 461.

Idris, Ivana.(2015). Aksesibilitas Difabel terhadap Bangunan Publik. Studi Perencanaan Lingkungan 2, Juni 2015

Jefri, Tamba. (2016). Aksesibilitas Sarana dan Prasarana bagi Penyandang Tunadaksa di Univeritas Brawijaya. Indonesian Journal of
Disability Studies 2016; Vol.3, No. 1, pp. 16 2516

Kadir, Syazwani Abdul, et al.(2012). Building Managers' Perception in Regards to Accessibility and Universal Design Implementation in Public Buildings: Putrajaya case studies Procedia - Social and Behavioral Sciences 35 pp. $129-136$

Magribi, La ode M. \& Suhardjo, Aj.(2004). Aksesibilitas dan Pengaruhnya terhadap Pembangunan di Pedesaan: Konsep Model Sustainable Accessibility pada Kawasan Perdesaan Di Propinsi Sulawesi Tenggara. Jurnal Transportasi Vol.4 No.2, pp. 149-160.

Mujimin, W.M. (2007). Penyediaan Fasilitas Publik yang Manusiawi bagi Aksesibilitas Difabel. Jurnal Dinamika Pendidikan No/Th.XIV Mei 2017, pp. 60-75.

Pajankar, Vishal D. (2016). A Case Study on Accessibility of School in Tribal Areas and Its Implications on Educational Inclusiveness. Journal of Educational and Practice, Vol 7, No.19, pp. 10-13.

Peraturan Menteri Pekerjaan Umum nomor 30/PRT/M/2006 tentang Pedoman Teknis Fasilitas dan Aksesibilitas pada Bangunan Gedung dan Lingkungan.

Salim, Choiri \& Yusuf, Munawir. (2009). Pendidikan Anak Berkebutuhan Khusus Secar Inklusif. Surakarta: Inti Media Surakarta

Sholahuddin, Muhammad.(2007). Setting Ruang dan Pengaruhnya terhadap Aksesibilitas para Penyandang Cacat Tubuh di Pusat Rehabilitasi YAKKUM Yogyakarta. Jurnal Lintas Ruang, Vol.1 Edisi 1, pp. 3141).

Syafiie, M.(2014). Pemenuhan Aksesibilitas Bagi Penyandang Disabilitas. Jurnal Inklusi, Vol.1, No. 2 Juli - Desember 2014 (270-289)

Tarsidi, Didi. (2008). Aksesibilitas Lingkungan Fisik Bagi Penyandang Cacat. Makalah disampaikan pada FGD Tentang Draft Raperda Perlindungan Penyandang Cacat Kota Bandung.Diunduh pada bulan Oktober 2017 disitu: http://file.upi.edu/. 
DOI:

Ulfa, dkk. (2016). Aksesibilitas Bagi Difabel pada gedung Pascasarjana Universitas Sebelas Maret. Jurnal Special_Edu Vol.2 No.1, pp.4351.

Undang-Undang Nomor 8 Tahun 2016 tentang Penyandang Disabilitas.
Widi, Narulita Anugrahing \& Nirwansyah, Rullan.(2013). Penerapan Aksesibilitas pada Desain Fasilitas Pendidikan Sekolah Luar Biasa. Jurnal Sains dan Seni Pomits Vol. 2, No. 2, pp.1-6 ISSN: 2337-3539. 